
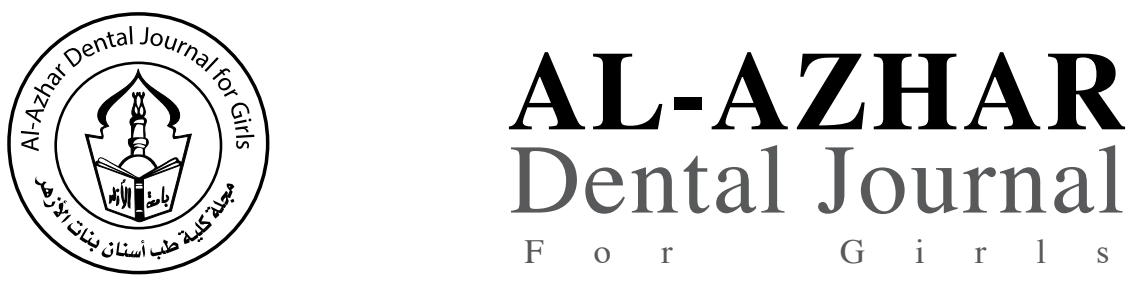

The Official Publication of The Faculty of Dental Medicine For Girls, Al-Azhar University Cairo, Egypt.

ADJ-for Grils, Vol. 4, No. 2, April (2017) — PP. 161:166

\title{
Effect of Two Different Collagen Cross Linking Agents versus Topical Fluoride on Management of Root Caries (In Vitro Study)
}

\author{
Sherihan A. Ismai'l (1), Maha A. Niazy (2) and Doaa A.E El-Sharkawy ${ }^{(3)}$
}

Codex : 20/1704

dentaljournal.forgirls@yahoo.com

Paper extracted from thesis

entitled: "Effect of Two Different

Collagen Cross Linking Agents

versus Topical Fluoride on

Management of Root Caries

(In Vitro Study)".

\begin{abstract}
Objectives: This study was designed to evaluate the effect of two different collagen cross linkers (GSE \& SA) versus topical fluoride, and the effect of exposure time of these agents on management of root caries. Material and Method: $48 \mathrm{hu}$ man premolar roots were used; the mesial or distal surface of each sample was ground flat to expose dentin surface, polished and then mounted on wax blocks. They were divided into 3 main groups $(n=16)$; A1: received 6.5\% GSE-treatment; A2: received $10 \%$ SA-treatment and A3: received topical $1.1 \% \mathrm{NaF}$ gel. Each group was divided into 2 subgroups $(n=8)$ according to treatment exposure time, where T1: was representing the short exposure time (10-min) and T2: was representing the long exposure time (30min). Each group was $\mathrm{pH}$-cycled for 3 constitutive days. Assessment was done using digital radiography (DR) and polarized light microscopy (PLM). Data was collected and statistically analyzed. Results: All agents used produced significant remineralization effect on the artificially demineralized root dentin following 30-min treatment, however the two collagen cross linkers produced significant mineralization effect after treatment for 10min. Conclusion: Using collagen cross linking agents could be of value to improve remineralization of root caries.
\end{abstract}

\section{INTRODUCTION}

The current trends in root caries management are to adopt preventive measures rather than restorative replacement. Remineralization of tooth hard tissues is now the preventive treatment of choice. Although fluoride is the current method used to prevent and inhibit caries lesions, its known side effects pushed researchers to find more natural alternatives ${ }^{(1-3)}$.

\section{KEYWORDS}

Collagen cross linkers, topical

fluoride gel, root caries,

pH-cycling.

1. Dentist at Dentist Training Center, Ministry of Health, El-Fayoum, Egypt.

2. Professor of Operative Dentistry, Faculty of Dental Medicine for girls, Al-Azhar University.

3. Assistant professor of Operative Dentistry, Faculty of Dental Medicine for girls, Al Azhar University. 
Recently, selective natural agents such as sodium ascorbate and proanthocyanidins have been proven to be biocompatible potent antioxidants and reported to stabilize and strengthen dentin by induction of exogenous collagen cross-links, interaction with non-collagenous proteins and remineralization. The presence of newly induced collagen cross links; prevents diffusion of minerals out of the carious lesion and acts as a template for mineral deposition, which in turn improves the mechanical properties of dentin ${ }^{(4-8)}$.

Because treatment time is a clinical challenge and due to the lack of definitive preventive approaches for root caries, the objective of this study was to evaluate the effects of two different collagen cross linkers (GSE \& SA) versus topical fluoride ( $1.1 \%$ neutral $\mathrm{NaF}$ gel) which was used as a positive control, and the effect of exposure time to these agents on management of root caries. Digital Radiography (DR) was used to evaluate the effect of the materials used (amount of mineral gain or loss expressed in radio-density) then Polarized Light Microscopy (PLM) was used to evaluate the depth of mineral-penetration (remineralization zone).

\section{MATERIALS AND METHODS}

Forty eight single rooted permanent human premolars free from caries, cracks or anomalies were selected from 45-70 years old patients who were not previously subjected to any topical fluoride application. The roots were separated from their crowns two millimeters coronal to the (CEJ), the mesial or distal surface of each sample was ground flat to expose dentin surface then polished using extra coarse polishing paper discs. Roots were then divided into three main groups $(n=16)$. Teeth were then stored in distilled water at room temperature $\left(25-30^{\circ} \mathrm{C}\right)$ to be used within the duration of 6 months ${ }^{(8)}$. The solutions were changed weekly until the teeth were used.
Standardized reproducible periapical radiographs for each sample were done before (at baseline) and after application of the acid and after application of the tested materials (post treatment). The image plate was scaned by Durr Vista scan and the image was saved in a digital folder. The saved images of each sample were interpreted to evaluate and record the pixel gray measurement (mineral content change). The mean value of six readings per sample was calculated to present the pixel grey measures of each image.

\section{Lesion formation}

Phosphoric acid gel $37 \%$ was applied to the exposed dentin surface of the sample for 2 minutes. It was then washed with water spray for one minute and then dried with gentle air from air way syringe ${ }^{(9-10)}$.

\section{Treatment \& pH cycling}

Initially all samples of each group were left into $150 \mathrm{~mL}$ of remineraliztion solution for 24 hours. The samples were then subjected to a 3-day treatment/ $\mathrm{pH}$ cycling scheme of 23 hours in remineralizing solution at $\mathrm{pH} 7.0$ and 1 hour in demineralizing solution at $\mathrm{pH} 4.3^{(11)}$.

\section{Preparation of the cross linking agents}

\section{- Preparation of $6.5 \%$ Grape Seed Extract (GSE) solution:}

GSE powder of 6.5 grams were weighed on balance sensor and dissolved in $100 \mathrm{ml}$ phosphate buffer saline (PBS) to make $6.5 \%$ proanthocyanidin solution, $\mathrm{pH}=7.4^{(\mathbf{1 2})}$.

\section{- Preparation of 10\% Sodium Ascorbate solution:}

Ten grams of sodium ascorbate powder were weighed on balance sensor and then were added to $100 \mathrm{ml}$ of PBS to make $10 \%$ sodium ascorbate solution, $\mathrm{pH}=7.4^{(\mathbf{1 3})}$. 


\section{Application of treatment agents \& pH-cycling model:}

The treatment $/ \mathrm{pH}$ cycling regimen lasted for 3 days and all the solutions were made fresh \& changed daily, the temperature of the solutions was adjusted to $37^{\circ} \mathrm{C}^{(\mathbf{1 1}, \mathbf{1 4}-15)}$ through the use of an automated shaker with incubator at constant shaking of 40 strokes/min .

\section{Image analysis}

Thickness of remineraliztion zone was measured on the obtained Photomicrographs using Image $\mathbf{J}$ program. Two length measurements were recorded from each image then averaged to obtain one reading per each specimen. Then the readings were transformed into micrometer. The data was recorded, tabulated and analyzed by computer with statistical program SPSS ver.17.0

\section{Polarized Light Microscopy Assessment:}

Three samples from each subgroup were sectioned longitudinally in buccolingual direction through the lesion on either side of pulp space.

\section{RESULTS}

\section{RADIOGRAPHIC RESULTS}

The highest statistically significant mean value of the percent change in radio-density was found with $(\mathrm{SA} / 30 \mathrm{~min})$, followed by $(\mathrm{NaF} / 30 \mathrm{~min})$, which showed no statistical significant difference when compared to (GSE/30 min). Moreover, (GSE/10 min) showed no statistical significant difference when compared with (SA/10 min) and both collagen cross linkers (GSE/10 min) and (SA/10 min) showed statistically significantly greater values when compared to (NaF/10 min). Regarding the effect of treatment exposure time; it was shown that the 30-min treatment produced significantly higher increase in mean value of the percent change in radio-density than treatment for 10-min regardless the reagent used [Table (1), Fig (1)].
Table (1) Effect of different variables interactions and their rankings:

\begin{tabular}{|c|c|c|c|c|}
\hline Material/time & Mean & S.D & Rank & $p$-value \\
\hline A1/T1 (GSE:;10min) & $6.7^{\mathrm{d}}$ & 1.5 & 18.50 & \multirow{6}{*}{$0.000^{*}$} \\
\hline A1/T2 (GSE;30min) & $10.9^{\mathrm{c}}$ & 2.8 & 31.25 & \\
\hline A2/T1 (SA; 10min) & $5.7^{\mathrm{e}}$ & 1.9 & 14.63 & \\
\hline A2/T2 (SA;30min) & $16.7^{\mathrm{a}}$ & 2.3 & 44 & \\
\hline A3/T1 (NaF;10min) & $3.5^{\mathrm{f}}$ & 0.9 & 5.88 & \\
\hline A3/T2 (NaF;30min) & $10.8^{b}$ & 1.4 & 32.75 & \\
\hline
\end{tabular}

*: Significant at $P \leq 0.05$, Different letters are statistically significantly different

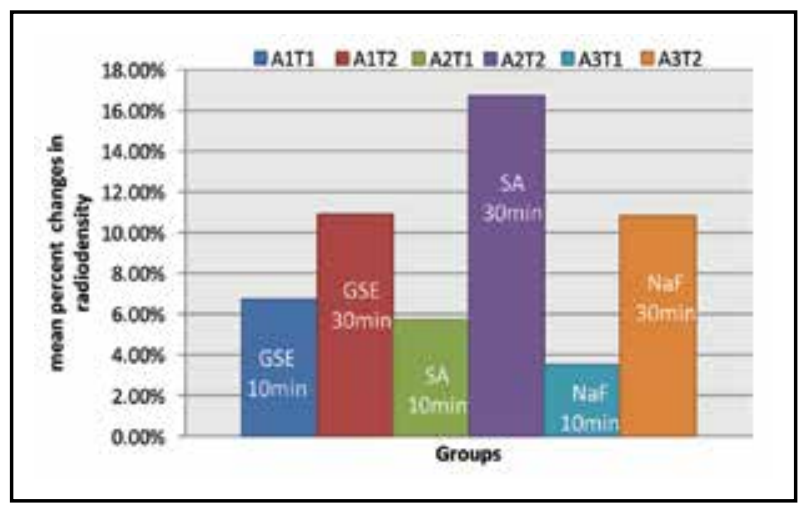

Fig. (1) All treatment groups arranged according to their mean percent changes in radio-density.

\section{Results of Polarized Light Microscopy:}

Thickness of remineraliztion zone (depth of mineral penetration) was measured using Image $\mathbf{J}$ program. PLM microphotographs revealed areas of remineralization varying from focal areas of different densities to wide translucent areas [Figure (2)]. For 10-min subgroups, GSE-treated group showed wider remineralization zone followed by SA- and then NaF-treated groups. The 30-min exposure time revealed a wider remineralization zone in SA-treated group followed by $\mathrm{NaF}$ and then GSE. Regarding exposure time, the remineralization zone was significantly increased when exposure time increased from 10-min to 30-min regardless the treatment agent used. 


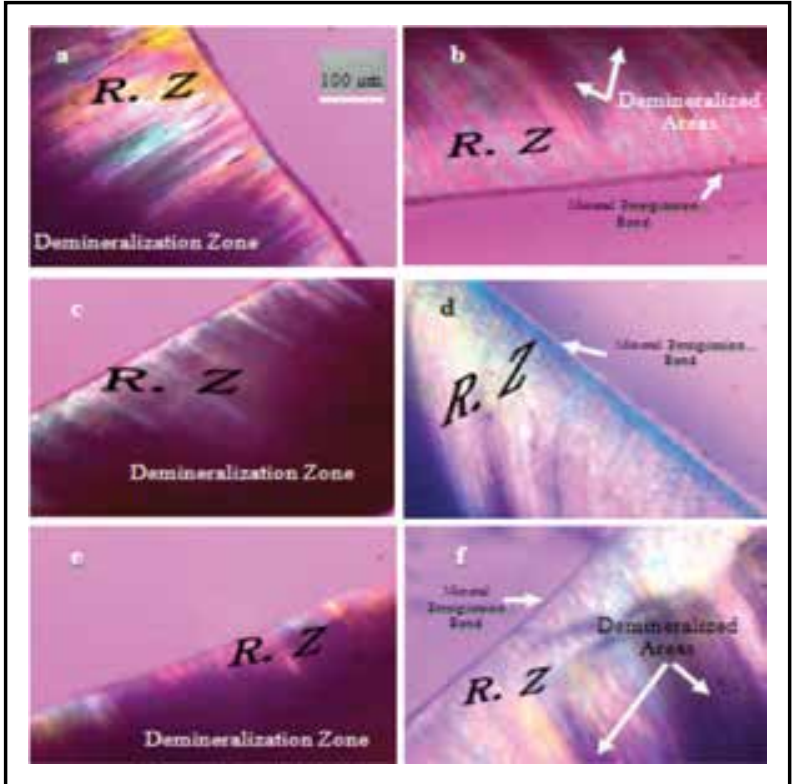

Fig. (2) Polarized light microphotograph of root dentin samples; a: GSE "10-min” treatment regimen, b: GSE "30-min" treatment regimen, c: SA 10-min treatment regimen, d: SA "30-min" treatment regimen, e: $\mathrm{NaF}$ "10-min" treatment regimen and f: NaF "30-min" treatment regimen. (R.Z): remineralization zone.

\section{DISCUSSION}

This study investigated the effect of two different collagen cross linkers (GSE \& SA) versus topical fluoride ( $1.1 \%$ neutral $\mathrm{NaF}$ gel) which was used as a positive control, and the effect of exposure time to these agents on management of root caries. Digital radiographic density measurement was used as it is a non-invasive method describes mineral gain or loss ${ }^{(16)}$.

Topical fluoride is has been shown in several previous studies to prevent and remineralize caries lesions in both enamel and dentin ${ }^{(17-19)}$. A high concentration of fluoride (5000 ppm) was used since the application of low concentration was found to form a precipitate (that occludes dentinal tubules ${ }^{(20)}$.

Sodium ascorbate [(SA); $(\mathrm{C} 6 \mathrm{H} 7 \mathrm{NaO})]$ is the sodium salt of ascorbic acid (vitamin $\mathrm{C}$ ) provides $131 \mathrm{mg}$ of sodium per $1,000 \mathrm{mg}$ of ascorbic acid.
It is a biocompatible and neutral antioxidant capable of quenching reactive free radicals in biological systems (21-22). The ascorbic acid is known to play significant role in biological functions and in vitro studies suggested that ascorbic acid is required for type I collagen matrix production and mineralization ${ }^{(23-24)}$.

On comparing the tested-materials, GSE- and SA-treated samples showed significantly higher mean values than fluoride for the 10-min treatment groups. However, for the 30-min subgroup, SAtreated group showed statistically significantly higher increase in mean values of the percent change in radio-density than that recorded in GSE- or NaFtreated groups. This could indicate that the three tested materials react in different ways to manage root caries. The potential remineralizing effect of GSE and SA may be attributed to the changes in the organic matrix, specifically by the presence of newly induced collagen cross-links.

The presence of exogenous collagen cross-links have been reported to increase collagen stability by reducing enzymatic degradation (25-27). However, the significant difference between the two collagen cross linkers after 30-min treatment, could be attributed to the additional biological importance of the ascorbate in tissue regeneration. This was reported by Malaval et al., $1994{ }^{(28)}$ who attributed the SA-effect in collagen matrix mineralization to its ability to induce an increase of the mRNA level for collagen type I, osteocalcin, bone sialoprotein, and alkaline phosphatase. Also, it has been shown that treatment with ascorbate enhanced the formation of mineralized nodules and collagenous proteins in vitro $^{(21)}$.

On comparing exposure time, 10min achieved significant remineralization effect although didn't reach baseline values. However, for the 30-min treatment regimen, all the tested materials achieved the "baseline" values. Fluoride seems to need more application time to produce the desired effect or F-treated samples demineralize faster when 
exposed to acid challenges. This was in agreement with previous studies which showed that permitting the patients to rinse, eat or drink within 30-min following topical fluoride application significantly reduced the fluoride content of artificially induced incipient lesions. As this could wash away the more soluble calcium fluoride or unreacted fluoride on the lesion surface before it is transformed into the more resistant FA form ${ }^{(29)}$.

PLM revealed areas of remineralization varying from focal areas of different densities to wide translucent areas. For 10-min subgroups, GSEtreated group showed wider remineralization zone followed by SA- and then NaF-treated groups. The 30-min exposure time revealed a wider remineralization zone in SA-treated group followed by $\mathrm{NaF}$ and then GSE. This could be attributed to the larger molecular size of GSE's PA which limits its further diffusion. This was in agreement with previous in vitro studies which attributed the limited penetration of minerals following GSE treatment due to the proanthocyanidin's chelating mechanism with calcium ions, which enhances mineral deposition on the surface of the dentin ${ }^{(30)}$, preventing further mineral deposition deeper within the lesion ${ }^{(25)}$.

\section{CONCLUSION}

It has been concluded that more exposure time with cross linking agent offers great advantage for efficient remineralization.

\section{REFERENCES}

1. Petti S and Scully C. Polyphenols, oral health and disease: a review. J Dent. 2009; 37(6):413-23.

2. Bedran-Russo AK, Castellan CS, Shinohara MS, Hassan L, Antunes A. Characterization of biomodified dentin matrices for potential preventive and reparative therapies. Acta Biomater. 2011; 7(4):1735-41.

3. Pavan S, Xie Q, Hara AT, Bedran-Russo AK. Biomimetic approach for root caries prevention using a proanthocyanidin-rich agent. Caries Res. 2011; 45(5):443-7.
4. $\mathrm{Xu} \mathrm{C}$ and Wang Y. Cross-linked demineralized dentin maintains its mechanical stability when challenged by bacterial collagenase. J Biomed Mater Res B Appl Biomater. 2011; 96(2):242-8.

5. Frencken JE, Peters MC, Manton DJ, Leal SC, Gordan VV, Eden E. Minimal intervention dentistry for managing dental caries- a review: report of FDI task group. Int Dent J. 2012; 62(5):223-43.

6. Bedran-Russo AK, Karol S, Pashley DH, Viana. Site specific properties of carious dentin matrices biomodified with collagen cross-linkers. Am J Dent. 2013; 26(5):244-8.

7. Bedran-Russo AK, Pauli GF, Chen SN, McAlpine J, Castellan CS, Phansalkar RS et al., Dentin biomodification: strategies, renewable resources and clinical applications. Dent Mater. 2014; 30(1):62-76.

8. Santos JN, Carrilho MRO, De-Goes MF, Zaia AA, Gomes BPFA, Souza-Filho FJ et al. Effect of chemical irrigants on the bond strength of a self-etching adhesive to pulp chamber dentin. J Endod. 2006; 32(11):1088-90.

9. Silverstone LM, Hicks MJ, Featherstone MJ. Dynamic factors affecting lesion initiation and progression in human dental enamel. Part I. The dynamic nature of enamel caries. Quintessence Int. 1998; 19(10): 92-102.

10. Nucã C, Bocskay T, Amariei C, Rusu L. Study regarding the histological features of enamel caries. OHDMBSC. 2005; 4(2): 5-12.

11. Borges FT, Reis W, Sant L, Nogueira A, Paiva SM, Magalhães $\mathrm{O}$ et al. Cariostatic effect of fluoride-containing restorative materials associated with fluoride gels on root dentin. J Appl Oral Sci. 2010; 18(5):453-60.

12. Benjamin S, Roshni, Thomas SS, Nainan MT. Grape seed extract as a potential remineralizing agent. A comparative in vitro study. J Contemp Dent Pract. 2012; 13(4):425-30.

13. Srinivasulu S, Vidhya S, Sujatha M, Mahalaxmi S. Effect of collagen cross-linkers on the shear bond strength of a self-etch adhesive system to deep dentin. J Conserv Dent. 2013; 16(2):135-8.

14. Hara AT, Magalhães CS, Serra MC, Rodrigues AL., Cariostatic effect of fluoride-containing restorative systems associated with dentifrices on root dentin. J Dent. 2002; 30(5-6):205-12.

15. Benjakul P, Prommontri $\mathrm{P}$, Chuenarrom $\mathrm{C}$, Leggat U. Effects of sour curry temperature with fermented shrimp paste on surface hardness of tooth enamel. Songklanakarin J Sci Technol. 2011; 33(4): 419-23. 
16. Ferreira RI, Haiter-Neto F, Tabchoury PM, Boscolo FN. In vitro induction of enamel subsurface demineralization for evaluation of diagnostic imaging methods. J Appl Oral Sci. 2007; 15(5):392-8.

17. Epstein JB, Van-Der-Meij EH, Lunn R, Stevenson-Moore P. Effects of compliance with fluoride gel application on caries and caries risk in patients after radiation therapy for head and neck cancer. Oral Surg Oral Med Oral Pathol Oral Radiol Endod. 1996; 82(3):268-75.

18. Walsh T, Worthington HV, Glenny AM, Appelbe $\mathrm{P}$, Marinho VC, Shi X. Fluoride toothpastes of different concentrations for preventing dental caries in children and adolescents. Cochrane Database Syst Rev. 2010(1): CD007868.

19. García-Godoy F, Lisa M,F, Catherine M, Hicks J. Fluoride dentifrice containing xylitol: In vitro root caries formation. Am J Dent. 2013; 26(1):56-60.

20. Suge T, Kawassaki A, Ishikawa K, Matsuo T, Ebisu S. Effects of ammonium hexafluorosilicate concentration on dentin tubule occlusion and composition of the precipitate. Dent Mater. 2010; 26(1):29-34.

21. Vaananen MK, Markkanen HA, Tuovinen VJ. Dental caries and mutans streptococci in relation to plasma ascorbic acid. Scand J Dent Res. 1994; 102(2):103-8.

22. Kaya $\mathrm{AD}$, Turkun $\mathrm{M}$. Reversal of dentin bonding to bleached teeth. Oper Dent. 2003; 28(6):825-9.

23. Dean DD, Schwartz Z, Bonewald L, Muniz OE, Morales $\mathrm{S}$, Gomez R, et al. Matrix vesicles produced by osteoblastlike cells become significantly enriched in proteoglycan- degrading metalloproteinadses after addition of betaglycerophosphate and ascorbic acid. Calcif Tissue Int. 1994; 54(5):399-409.

24. Ogawara M, Aoki K, Okiji T. Effect of ascorbic acid deficiency on primary and reparative dentinogenesis in non-ascorbate -synthesizing ODS rats. Arch Oral Biol. 1997; 42(10-11):695-704.

25. Xie $\mathrm{Q}$, Bedran-Russo $\mathrm{AK}, \mathrm{Wu} \mathrm{CD}$. In vitro remineralization effects of grape seed extract on artificial root caries. $J$ Dent. 2008; 36(6):900-6.

26. Castellan CS, Bedran-Russo AK, Karol S, Pereira PN Long-term stability of dentin matrix following treatment with various natural collagen cross-linkers. J Mech Behav Biomed Mater. 2011; 4(7):1343-50.

27. He L, Mu C, Shi J, Zhang Q, Shi B, Lin W. Modification of collagen with a natural cross-linker, procyanidin. Int J Biol Macromol. 2011; 48(2):354-9.

28. Malaval I, Modorowski D, Gupta AK, Aubin JE. Cellular expression of bone-related proteins during in vitro osteogenesis in rat bone marrow stromal cell cultures. $\mathrm{J}$ Cell Physiol. 1994; 158(3):555-72.

29. Stookey GK, Schemehorn BR, Drook CA, Cheetham $\mathrm{BL}$. The effect of rinsing with water immediately after a professional fluoride gel application on fluoride uptake in demineralized enamel: An in vivo study. Am Acad Ped Dent. 1986; 8(2)153-7.

30. Fine AM. Oligomeric Proanthcyanidin complexes: History, structure and phytopharmaceutical applications. Altern Med Rev. 2000; 5(2):144-51. 